\title{
THE WARSHIP ASSIGNMENT SCHEDULE USING INTEGER PROGRAMMING MODEL
}

\author{
Ahmadi $^{1}$, Benny Sukandari ${ }^{2}$, Agus Makhrowi $^{3}$ \\ 1, 3 Indonesian Naval Technology College, \\ Bumimoro-Morokrembangan, Surabaya 60187, Indonesia \\ ${ }^{2}$ Naval Command and Staff College Cipulir, Seskoal Jakarta, 12230, Indonesia
}

\begin{abstract}
Scheduling is an assignment activity that deals with constraints. A number of events can occur in a period of time and location so that objective functions as close as possible can be fulfilled. In the hierarchy of decision making, scheduling is the last step before the start of an operation. Scheduling warship assignments in Kolinlamil are an interesting topic to discuss and find solutions to using mathematical methods. The process of the Kolinlamil warship assignment schedule was carried out to produce an annual shipbuilding schedule. This process not only requires fast follow-up, but also requires systematic and rigorous steps. Where the assignment schedule is a fairly complex combinatorial problem. While making the assignment schedule that is applied at this time is considered less accurate because it calculates the conventional method. The process of warship assignment schedule in this study using the Integer Programming model aims to obtain alternative scheduling operations. The schedule observed was 13 warships in carrying out N operations for 1 year (52 weeks). This research begins with determining the decision variables and limitations that existing constraints. Hard constraints include: maintenance schedule, time and duration of each task, warship class assigned to the task and the number of executing warships per task. While soft constraints are how long the warship performs its tasks in a row. The mathematical formulation of the Integer Programming model created consists of three indicator, one decision variables, two measuring parameters and five constraint functions. Furthermore, determining the best scheduling alternatives is completed using the Microsoft Exel Solver computing program.
\end{abstract}

Keywords: Scheduling, Integer Programming, Solver.

\section{INTRODUCTION.}

Komando Lintas Laut Militer (Kolinlamil) is the main command in the field of development and operations. In the development field, Kolinlamil compiled and planned the development of warship (KRI) elemental strength programs, terminals and supporting facilities and infrastructure within the Kolinlamil range. Whereas in the operational field, Kolinlamil was tasked with preparing a plan and implementing a sea transportation program for all ranks of the TNI and Polri and other agencies. Sea transportation is administrative and strategic tactics which include transportation of personnel, equipment and supplies, and carrying out sea transportation assistance in all Indonesian waters. Kolinlamil warships can be operated both in times of war and peacetime in order to support national development and can be carried out individually or in formation.

The Kolinlamil annual operation plan was prepared with TNI Headquarters and Navy Headquarters. The planning of warship operations is adjusted between the number of personnel, material, and the area that will be the destination and class of the warship. So that the warship will be used in accordance with the needs of the task to be carried out, both in terms of class and the number of warships. Based on the annual operating plan, Kolinlamil in this case the Operations Staff (Sops) Kolinlamil made a schedule of assignments for the warship in one year (52 weeks) to support operations. This schedule is made for posting planned operational tasks so that the ship is carrying out the operation and the ship carrying out the maintenance.

In order for all ships to be ready to carry out all planned operational tasks, both in terms of class of the ship and the amount needed, the operational and maintenance schedules need to be prepared and made before the operation. So that in making the warship assignment schedule and preparation needed to carry out operations, Sops Kolinlamil determines the class of the warship and the amount to be operated and always considers the ship maintenance schedule. In this case Sops coordinated with the Ship Maintenance Service (Disharkap) Kolinlamil as a warship maintenance schedule maker. The warship assignment schedule is made taking into account the ship maintenance schedule aimed at keeping the ship in top condition and ready to operate, so that all operational tasks run effectively and efficiently.

At present the creation of an operational assignment schedule still results in a program crash that results in violations of operating restrictions and rules. Among them resulted in a delay in the warship maintenance schedule and there is a violation of the maximum operating time constraints. There is a warship that has received a new order to carry out further duties when the warship has finished carrying 
out operations, even though it has exceeded the maximum deadline for the operation.

So that the warship assignment schedule is made by considering the limitations of infrastructure facilities that are faced in each task as well as the rules for carrying out warship operations. These limits and rules include: class of warships according to the needs of the task, maintenance of the warship according to schedule, start and duration of time to carry out specified tasks, one warship only performs one task at the same time and the maximum execution time of consecutive warship is 3 months (12 weeks).

This research has various references, including: (Solekan, 2016) conducted a research on the assignment of warships in Kolinlamil using the Binary Integer Programming (BIP) method aimed at minimizing penalties if violating the soft constraints (the length of operation of the ship in a row) that were completed using LINGO 11.0. (Šeda, 2007) uses the Mixed Integer Programming (MIP) method, by presenting mathematical models for permutation of flow shop scheduling and proposed job shop scheduling problems. (Hidayat, 2018) research that aims to get the best alternative in order to optimize the schedule of assignment plans for warship in order to produce JOG / JOP by developing an optimization model and applying the Integer LinearZero One Programming method.

The warship scheduling model is a fairly complex combinatorial problem with many variables so that it is difficult to process manually. Therefore the authors are interested in conducting research to create an Integer Programming model with completion using the Microsoft Exel computing program from the warship assignment schedule in Kolinlamil to get the best alternative scheduling solution. So as to get the best schedule by increasing infrastructure facilities owned by Kolinlamil, TNI AL or other agencies.

\section{MATERIALS AND}

\section{METHODS. 2.1 Warship.}

Warships are ships used for military or armed forces. Generally divided into aircraft carriers, combatant ships, patrol ships, transport ships, submarines and supporting ships.

At this time Kolinlamil operates various types of transport warships, including: Landing Ship Tank (LST), FROSCH / Angkut Tank Frosch (ATF), Landing Platform Dock (LPD), COASTER / Bantu Umum (BU) and Bantu Angkut Personel (BAP). The grouping of warships is intended to focus on the priority scale of the warship as needed to support, according to the functions and capabilities of each warship (TNI-AL, 2005). In this study Kolinlamil has 13 warships, but there are 3 warships that can not be used because they are in conservation status.

\subsection{Scheduling.}

According to (Baker, 1974) scheduling is the allocation of resources to carry out a set of time- based tasks. Scheduling problem solving must at least answer two forms of questions, which are the resources that will be allocated to work on the operation and when each operation starts until completion. Scheduling is one of the important aspects of operations management because good scheduling will make the organization able to use its assets or resources more efficiently and have a positive effect on achieving its objectives (effective). In other words, resource utilization will be better when the organization can know when and how much capacity is still idle. With the same resources, the capacity of the organization becomes "bigger" with more output. From the potential benefits, organizations will be able to have a competitive advantage by doing good scheduling. Even this one scheduling concept can contribute to achieving better, faster, cheaper, and reliable services at the same time. A good schedule should be simple, easy to understand and can be implemented by the management or anyone who uses it. Scheduling rules should be strong enough, but have realistic goals, so they are flexible enough to solve unpredictable problems and allow for re-planning.

In this study classified into Middle-range planning level activities, namely in the span of 1-2 years. The scheduling approach used in this study is a forward scheduling approach, is when the job is scheduled for the moment of arrival, or when it is ready or at zero (time zero) and moves forward towards the due date in weeks. Where an operational task is scheduled when the warship is ready to carry out operations for a certain duration and by using all available resources to the maximum without violating the rules that have been made.

\subsection{Integer Programming (IP).}

Integer Programming (IP) is Linear Programming (LP) with variables of type integer. The IP model is chosen for problems that are more difficult than the LP model. This is because there are many combinations of integer values that must be tested, and each combination requires a normal LP or NLP solution. With the main point of mind in IP is to formulate the problem clearly using a number of available information. And the next step is to translate the problem into a mathematical model.

Optimal scheduling can be obtained by using the IP scheduling technique and using the Priority Dispatching Heuristic approach. The rules for the Priority Dispatching method are used to fulfill which tasks will be done first The rules for the Priority Dispatching method are used to fulfill which tasks will be done first. Classification of assignment priorities based on dynamic information. Different priorities are given for each warship on a task. The highest priority is given to warships that have the greatest success rate in an operational task, and so on. 


\subsection{Methodology.}

This study uses a case study of the assignment schedule for the Kolinlamil warship. The research approach uses a quantitative approach by developing mathematical models and theories related to empirical observation. The approach of this research is to create an Integer Programming
(IP) model to find the best alternative so that it gets more optimal scheduling.

\subsubsection{Research Flow Chart.}

This research was conducted based on the research methodology framework that can be seen in Figure 1, below this:

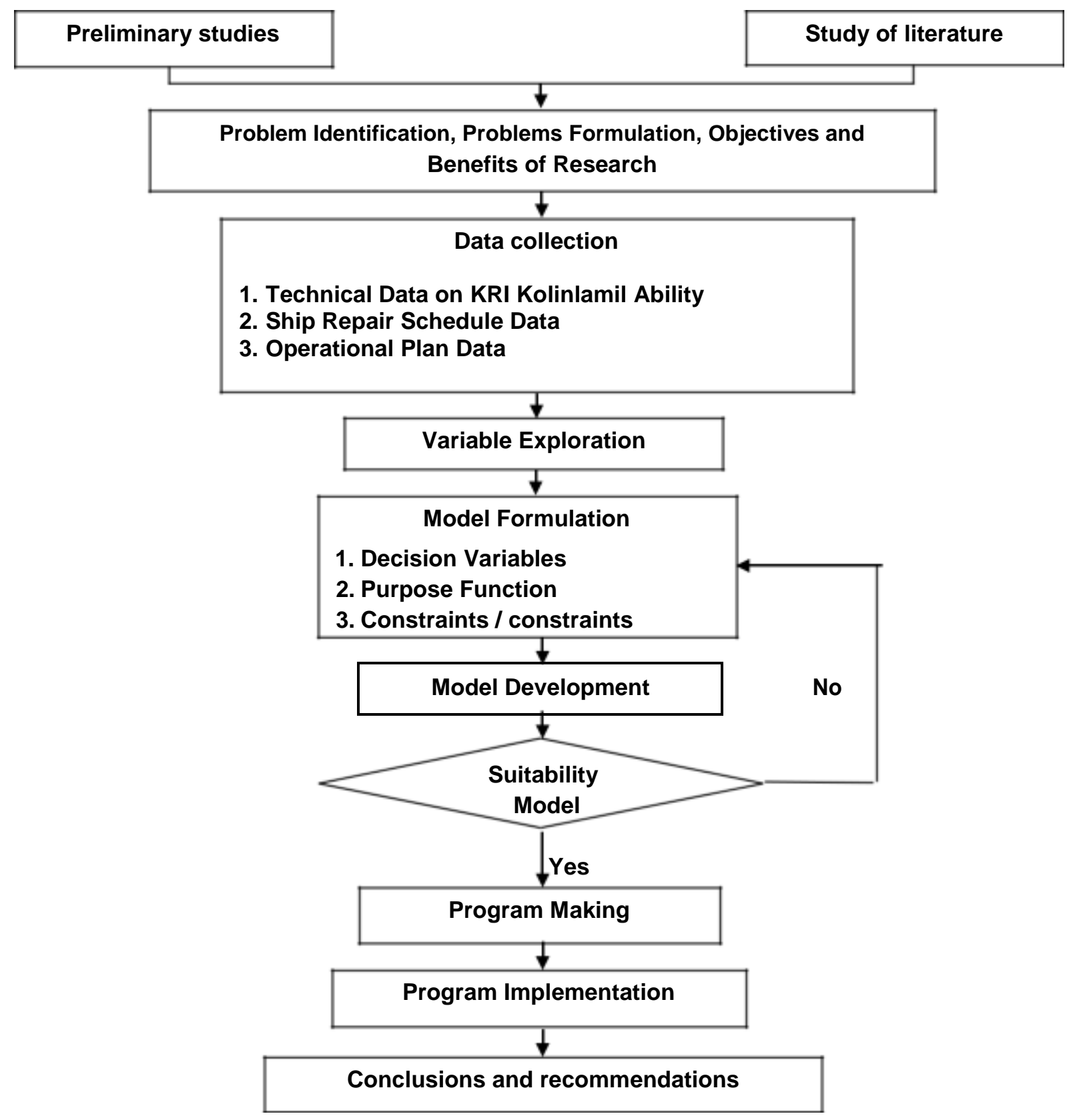

Figure 1 Research Flow Chart

\subsubsection{Variable Exploration.}

At this stage is carried out identification of influential variables by observing problems related to the model. Warship assignment model variables are as follows:

a. Indicator

$i \quad=$ Warships carrying out operations (1......13).

$j \quad=$ Operations performed $(1 \ldots \ldots . n)$. $k=$ Scheduling period $/$ length of time in weeks $(1 \ldots . .52)$

b. Decision Variable

$$
\begin{aligned}
X_{i j k}= & 1, \text { If ship to- } i \text { is scheduled to carry } \\
& \quad \text { out operations to- } j \text { on the first week. } \\
= & \quad 0, \text { If not. }
\end{aligned}
$$


c. Parameter

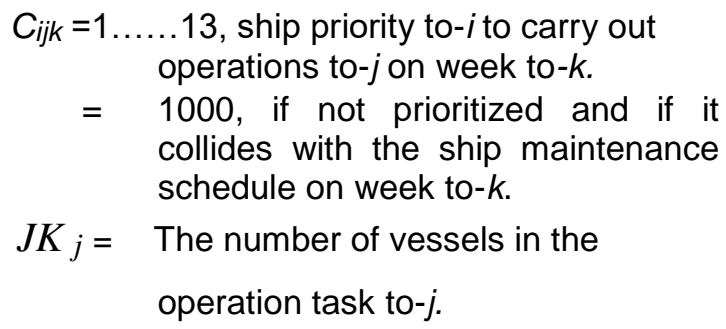

\subsubsection{Model Formulation.}

Integer Programming (IP) is an approach used in solving linear programming problems, but requires additional boundaries, namely some or all decisions are integers. The IP model of the ship assignment scheduling problem consists of objective functions and constraint functions. The objective function is a function used to formulate the objectives to be achieved, both the goal of maximizing and minimizing. While the constraint function is a limiting function related to the limited available resources and existing rules.

a. The first step

This research method aims to optimize the assignment of 13 warships to each assignment with an IP optimization model which can be formulated as follows:

\section{Decision Variable}

The optimization decision variable of this study is the assignment of a warship or several warships to each operation task. The form of the decision variable is Binary 0-1 (zero-one). Result 0 means that ship to- $i$ is not assigned to task to- $j$ and result 1 means ship to- $i$ is assigned to task to-j.

2) Purpose Function

Minimizing $Z$ to get the highest priority warship in carrying out an operation task.

\section{3) System Limitation Function (Constraint)}

In operations planning there are several obstacles that must be faced, both hard constraints and soft constraints. These constraints include:

a) Class of warships carrying out operations. Warship class constraints that carry out operations mean that the warship carrying out each operation has a class of abilities or certain characteristics adapted to the needs of the operation task. In this study using the Priority Dispatching method.

b) Warship maintenance schedule constraints. Each warship must carry out maintenance, according to the warship maintenance schedule planned by
Disharkap, which is the week of how maintenance starts and how long it takes.

c) Operating duty schedule constraints. Every operational task has been determined or planned from the TNI Headquarters and the Indonesian Navy Headquarters, namely the week of how the operation will start and how long it will take.

d) Constraints clashed operating schedule. Each ship only carries out one operation task at a time, in other words, the ship does not carry out more than one operation at a time.

e) Constraints on the number of warship needs in one operation. In carrying out one task the exercise operation sometimes requires more than one warship according to the training needs.

f) Constraints on the maximum execution time of the warship's operations in a row. Each warship in carrying out operations must not exceed 3 months or 12 consecutive weeks in an effort to maximize the achievement of the task.

\section{b. Second Step}

Data from the results of mathematical formulations the first step is then carried out computational calculations from the computer program Solver Microsoft Exel. The computer program aims to obtain optimal results quickly from the data from the first step that has been obtained. And then implementing a computer program in the example case in completing the scheduling assignment of warship in Kolinlamil.

\section{RESULT AND DISCUSSION.}

The IP model of the problem of this ship assignment schedule consists of objective functions and constraint functions. The objective function is a function that is used to formulate the objectives to be achieved, namely minimizing the priority of ships carrying out operations. Whereas the constraint function is a necessary limiting function with regard to the limited available resources, for example the number of ships, the time available, the ability of the ship, the task load and adjusted to the maintenance plan that will and should be done.

\subsection{Warship Maintenance Schedule.}

In making maintenance schedules, each warship planned to carry out the repair / maintenance process on that week gives a large number, for example 1000. Whereas warships that did not carry out repairs / maintenance on that week were given number 1 . The ship maintenance schedule can be seen in the following figure 2 : 


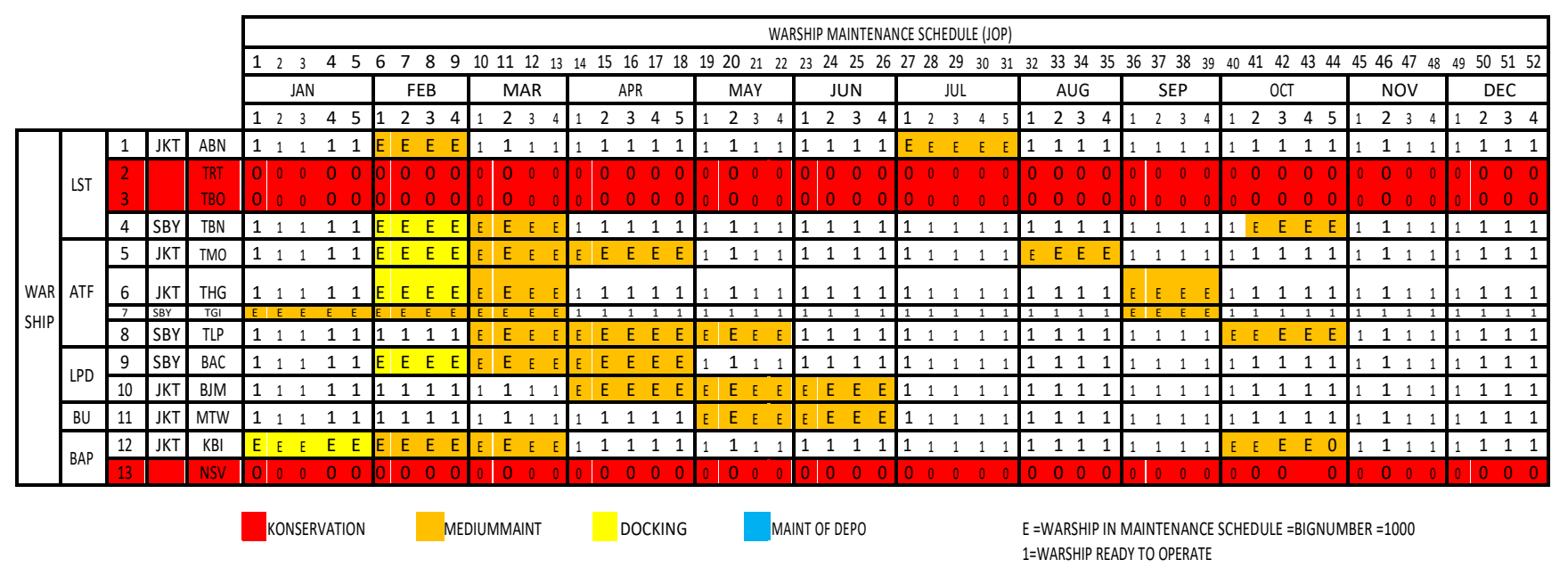

Figure 2 Matrix of Warship Maintenance Schedule (Source: Maintenance schedule for warship Kolinlamil 2018)

3.2. Operational Plan Schedule.

In making the operational plan schedule, each operation assignment plan from the beginning to the end of the week's assignment is given a number 1 . Whereas the warship does not carry out the operation in the week given the number 0 . The operational plan schedule can be seen in figure 3 below:

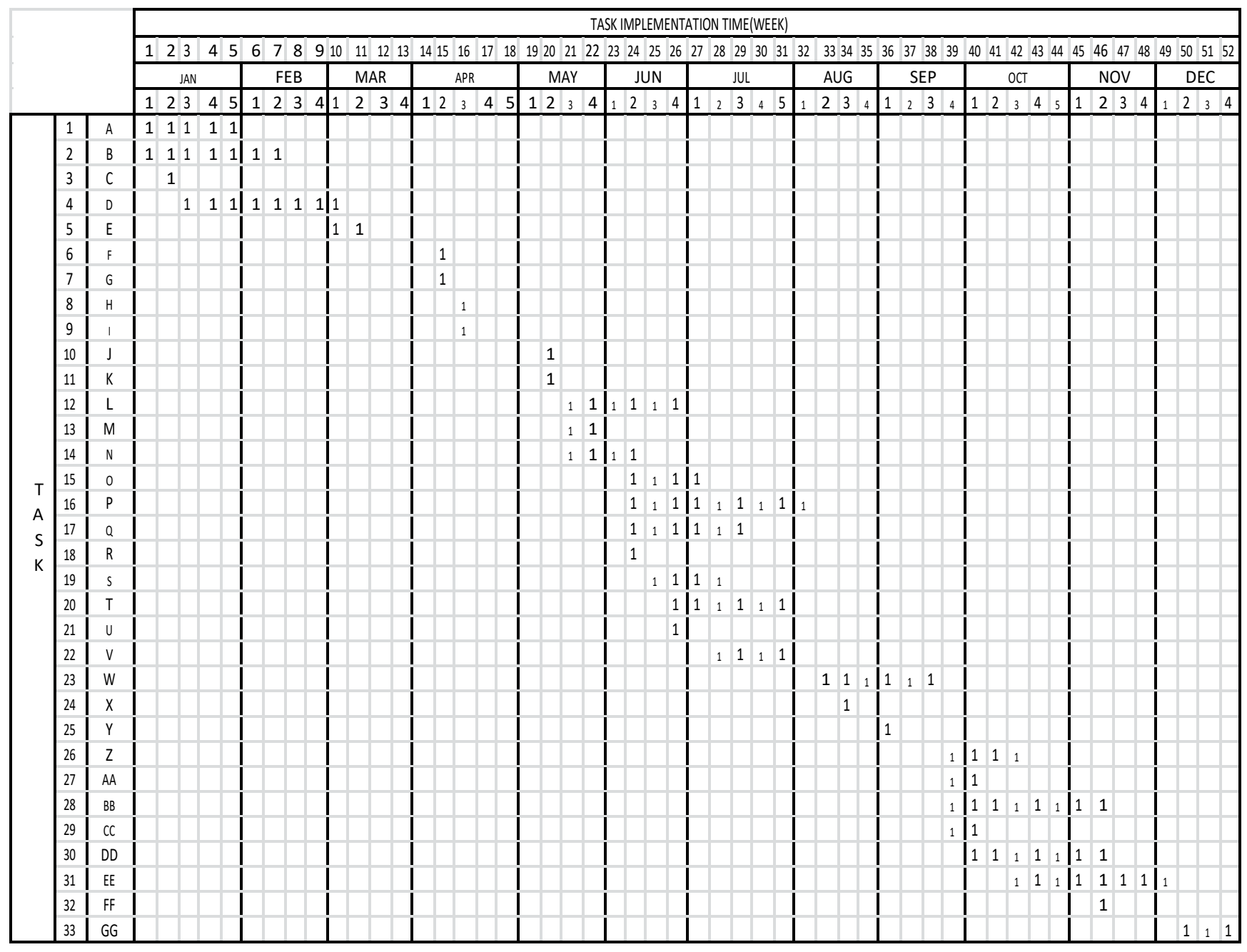

Figure 3 Schedule of Operational Assignment Plan Matrix (Source: Schedule of warship Operation Plan for Kolinlamil 2018) 


\subsection{Priority of Warships Carrying Out Operations.}

Giving priority warship executing tasks means that the warship has a capability class or characteristics that are tailored to the needs of the operation task. In making priority warships planned to carry out operations, each warship in each task planned for the week is numbered according to priority. The main priority is given number 1 and so on up to the last priority number 10 according to the number of warships. Or given the number 1000 if the warship is not prioritized on the task. The results of data processing are presented in table 1 below:

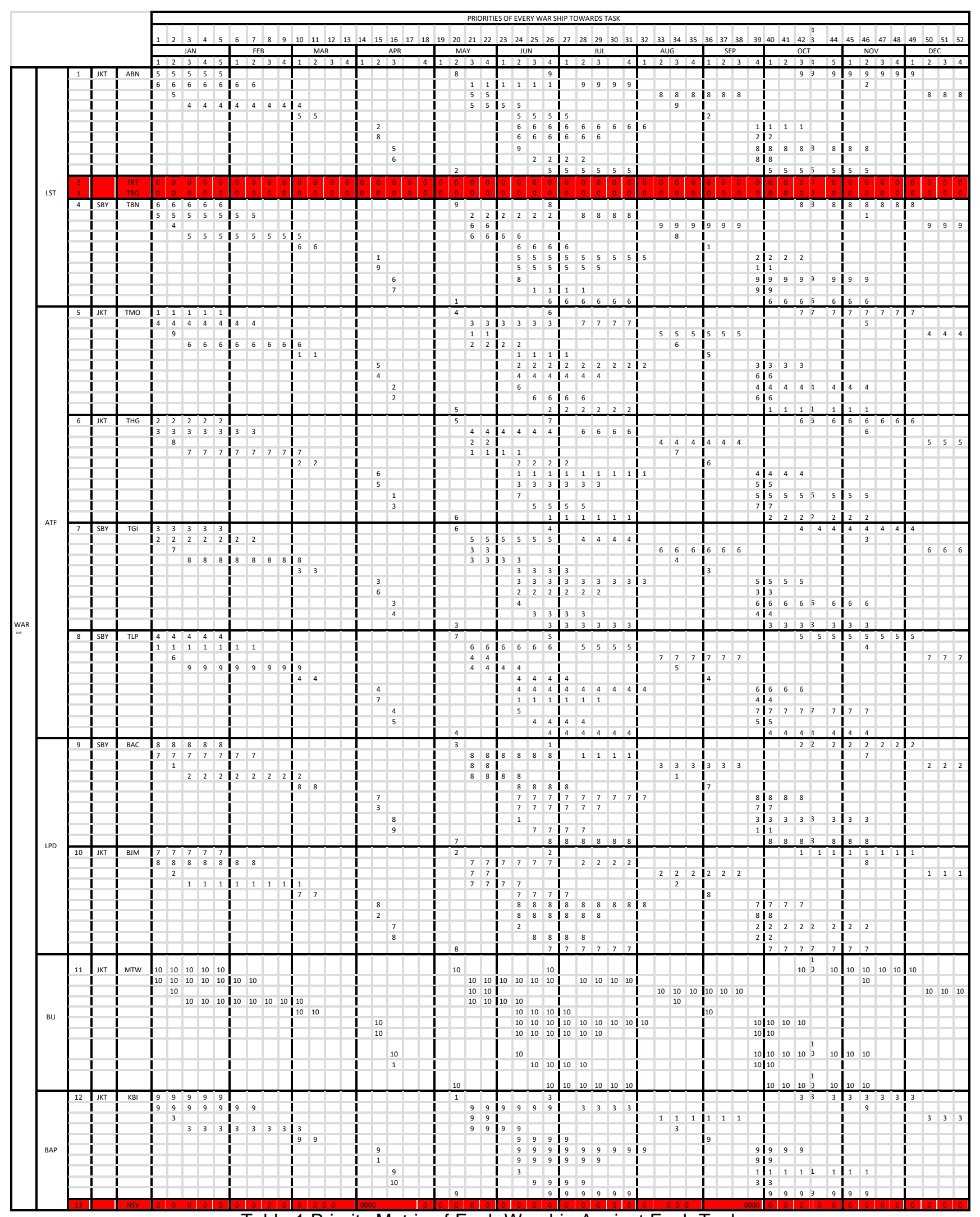


Priority of ships that have been made is faced with obstacles to schedule ship repairs and other constraints and assignment rules. The results of data processing are presented in the following table 2:

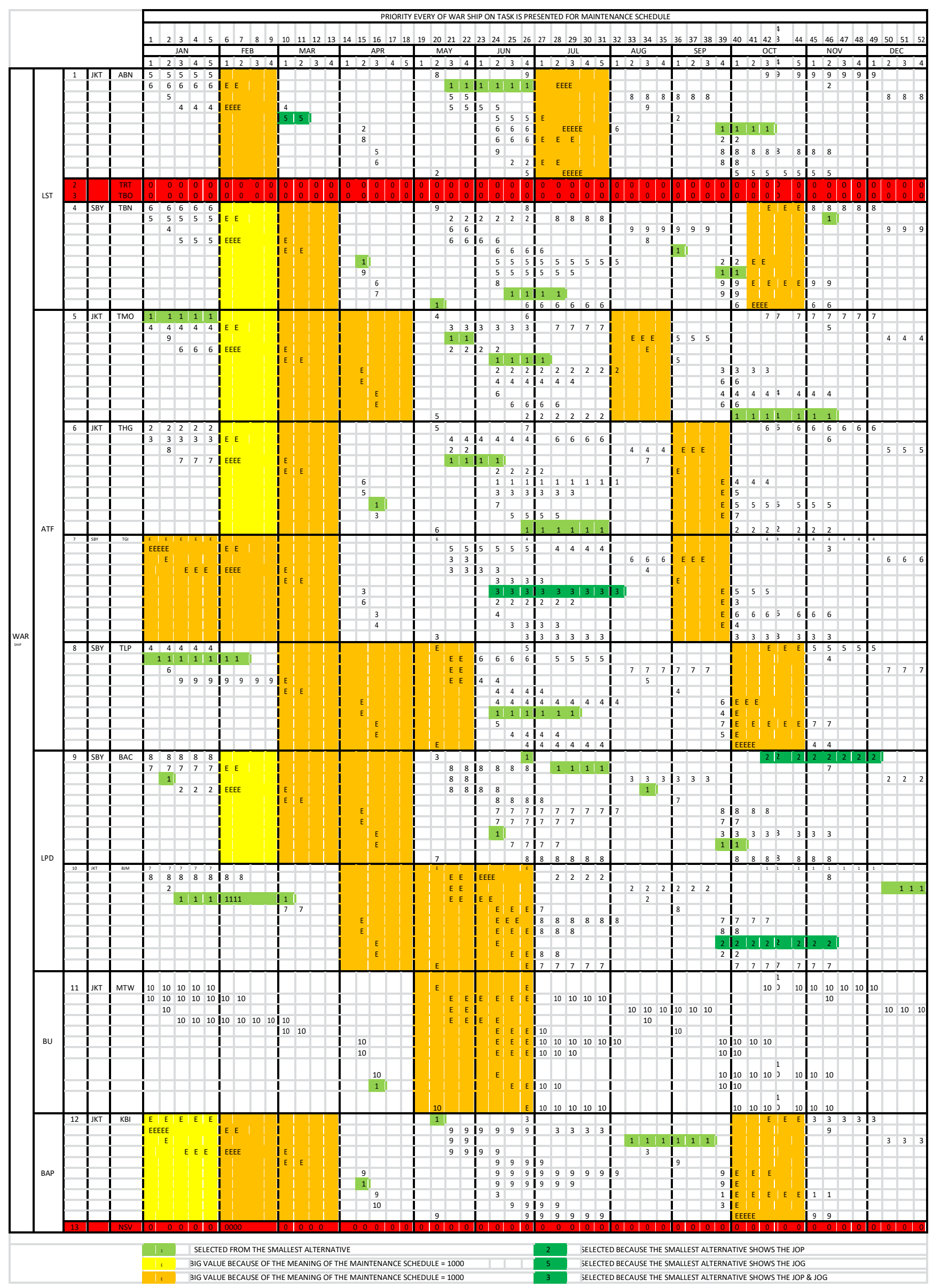




\subsection{The Final Result.}

The final results of processing the scheduling of the activities of each warship for one year (52 weeks). The results of data processing are presented in table 3 below:

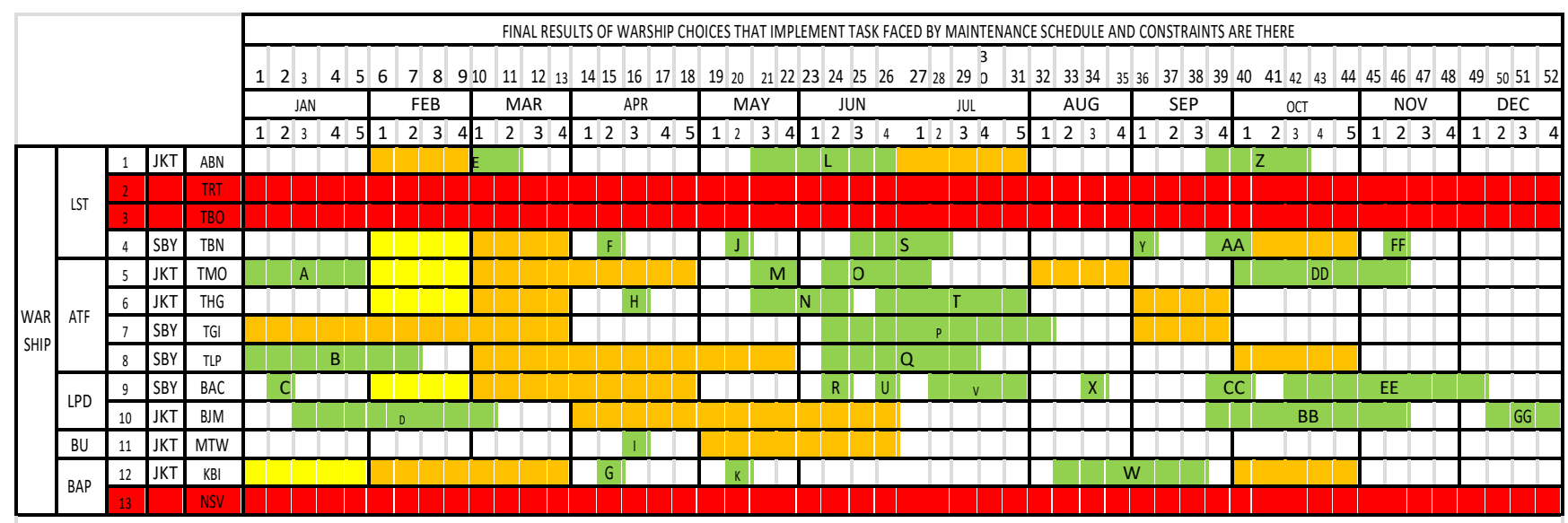

IMPLEMENTINGOPERATION TASKS

Table 3 Final Result Matrix of The Kolinlamil Warship Schedule

\subsection{Model Validation.}

Validation was carried out between the conceptual models made by the researcher on the scheduling of warship assignments in Kolinlamil at this time. Warship assignment scheduling currently occurs that the assignment schedule still violates the existing constraints, namely first on hard constraints (violating the warship maintenance schedule) and violating soft constraints (maximum length of the warship carrying out operations in succession). While the warship assignment schedule from the results of running modeling made by researchers can be used as an alternative to actualize. The model made has advantages compared to the existing schedule, namely scheduling ship assignments not violating hard constraints or soft constraints.

\subsection{Sensitivity Analysis.}

Scheduling of warship assignments in Kolinlamil use 13 warships (10 operating ships and 3 conservation status vessels), to carry out 33 operations and maintenance schedules for 52 weeks. Different patterns will occur if the warship in operation is reduced. The results after the changes are made are operating schedules and compared to the operating schedule with the total number of warships. In addition, analysis of changes / reductions in the number of warships operated. How many warships can be operated so that the results obtained remain optimal by not breaking hard constraints and soft constraints.

Scenario 1: warships are reduced by 1 unit from the LST class so that the warship operating as many as 9 warships, the results obtained by the ship can still carry out operations optimally.

Scenario 2: warships are reduced by 1 unit from the ATF class so that the warship operating as many as 9 warships, the results obtained by the ship can still carry out operations optimally.
Scenario 3: warships are reduced by 1 unit from the LPD class so that the warship operating as many as 9 warships, the results obtained by the ship can still carry out operations optimally.

Scenario 4: warships are reduced by 1 unit from the BU class so that the warship operating as many as 9 warships, the results obtained by the ship can still carry out operations optimally.

Scenario 5: warships are reduced by 1 unit from the BAP class so that the warship operating as many as 9 warships, the results obtained by the ship can still carry out operations optimally.

Scheduling of warship assignments using models made by researchers can be done with optimal results or in other words, there are no obstacles that are violated when the number of warships is at least 9 units. But if there are only 8 warships in operation, there will be obstacles that will be violated.

\section{CONCLUSIONS.}

From a series of data processing and analysis carried out in this study the following conclusions can be drawn:

a. Making a schedule of operations tasks in Kolinlamil by fulfilling all obstacles can be applied using IP.

b. Scheduling assignments of warship using the IP program are better at fulfilling all applicable constraints, because it produces a compromise schedule with all the related constraints and meets the applicable regulations.

c. The time needed for the preparation of the warship assignment schedule and the time of making several warship assignment schedule scenarios that still meet the applicable regulations, are more efficient than the scheduling of warship assignments currently carried out.

d. This warship assignment schedule model can be used as an alternative in scheduling warship operations in Kolinlamil. 
IP is a method used to model problems whose variables are not real numbers. While the decision from IP in the form of binary numbers is worth 0-1 For further development the implementation of this scheduling is as follows:

a. The author only supports the warship assignment schedule and has not included operating costs, both logistical costs for the warship and logistics costs for guarding personnel and transported personnel, so this can be continued for the next research study to include these costs because by knowing the costs used then it can be searched for the most efficient cost in an operation.

b. The author also does not review the addition of operational assignments that can affect the existing and already made schedules. So that it can be known how many additional assignment limits can be imposed on Kolinlamil.

\section{REFERENCES}

Andersson, H., Jon, M. D., \& Fagerholt, K. (2011). Ship Routing And Schedulling With Cargo Coupling And Synchronization Constraints. Computer \& Industrial Engineering, 61(4), 1107-1116.

Baker, KR. (1974), Scheduling a full time workforce to meet cyclic staffing requirements, Management science 20, 1561-1568.

Carlatfis et al. (2009). Containership routing with time deadlines and simultaneous deliveries and pick-ups. Journal Transportation Research, Part E 45, pp. 210-221.

Chen, T., Li, J., Jin, P., \& Cai, G. (2012). Reusable Rocket Engine Preventive Maintenance Schedulling Using Genetic Algorithm. Science Direct, Relliability Engineering \& System Safety.

Christiansen, M., Fagerholt, K., Nygreen, B., \& Ronen, D. (2013). Ship Routing And Schedulling In he New Millenium. European Journal of Operational Research, 228(3), 467-483.

Deris, S., Omatu, S., Ohta, H., \& PA, S. (1999). Ship Maintenance Schedulling By Genetic Algorithm and Constraint-Based Reasoning.
Sience Direct, European Journal of Operational Research, 489-502.

Fetanat, A., \& Shafipour. (2011). Generation Maintenance Scheduling In Power System Using Ant Colony Optimization For Continous Domain Based 0-1 Integer Programming. Expert System With Application, 38(8), 9729-9735.

Hidayat, A. (2018). Optimization Model of Warship Assignment Scheduling to Secure The Koarmada II \& Koarmada III Sea Region. Surabaya: Indonesian Naval Technology College.

Keneth, R. B. (1974). Scheduling a Full-Time Workforce to Meet Cyclic Staffing Requirements. Management Science, 15611568.

Maras, at al. (2013). Routing of Barge Container Ship by Mixed Integer Programming Heuristics. Applied Soft Computing, 13, pp. 3515-3528.

Salmeron, J., \& Dufek, M. (2014). Optimization Of Continuous Maintenance Avability Scheduling. Naval Postgraduate School, Operations Research, Monterey, California.

Šeda, M. (2007). Mathematical Models of Flow Shop and Job. International Journal of Applied Mathematics and Computer Sciences, 4, 241-246.

Solekan, M. (2016). Scheduling of KRI Assignments in Kolinlamil With The Binary Integer Programming Approach. Surabaya: Indonesian Naval Technology College.

T'kindt, V. \& Billaut, JC. (2002). Multicriteria Scheduling: Theory. Models, and Algorithms. Springer. New York.

Wen, M., Ropke, S., Peterson, H. L., Larsen, R., \& O, B. G. (2016). Full-Shipload Tramp Ship Routing and Scheduling with Variable Speeds. Computer \& Operation Research, $70,1-8$. 